\title{
CORPO, GÊNERO E BELEZA: O QUE A EDUCAÇÃO INFANTIL TEM A VER COM ISSO?
}

\author{
Narda Helena Jorosky ${ }^{1}$, Marta Campos de Quadros ${ }^{2}$, Maria de Fátima Salum Moreira ${ }^{3}$ \\ ${ }^{1}$ Faculdades Integradas de Ourinhos, mestranda em Educação na Universidade do Oeste Paulista - UNOESTE, \\ Presidente Prudente - SP. ${ }^{2}$ Bolsista de Pós-doutoramento CAPES/PNPD junto ao Programa de Pós-Graduação em \\ Educação da UNESP - Presidente Prudente - SP. ${ }^{3}$ Universidade do Oeste Paulista - UNOESTE, Programa de Pós- \\ Graduação em Educação, Presidente Prudente - SP. E-mail: fatimasalum@gmail.com hjorosky@hotmail.com
}

\section{RESUMO}

O artigo resulta da interação entre as pesquisas que as autoras desenvolvem no âmbito da Educação em articulação com os estudos da cultura (visual) e com base nas teorias da linguagem de Bakhtin e de cultura visual segundo Hernandez. Visa-se investigar as imagens que circulam contemporaneamente e suas associações com as diferentes concepções de beleza, gênero e corpo. Mais especificamente, nos interessa analisar o modo como essas imagens interpelam as crianças pequenas na educação infantil e as suas implicações nas relações de gênero e do tipo de sujeito que se forma, bem como as concepções de beleza, corpo e gênero construídas pelas crianças. A partir da abordagem do debate acadêmico no tema, temos por objetivo: analisar os processos envolvidos nas apropriações feitas pelas crianças das imagens do corpo feminino e masculino e suas relações com os padrões de beleza e normalidade que circulam em seus espaços educativos e não educativos.

Palavras-chave: infância, corpo, beleza, educação infantil, gênero

\section{BODY, BEAUTY AND GENDER: WHAT EARLY CHILDHOOD EDUCATION HAS TO DO WITH IT?}

\begin{abstract}
The article is the result of interaction between the research that the authors develop within the Education in conjunction with the studies of (visual) culture and based on the language theories of Bakhtin and visual culture of Hernandez. It aims to investigate the contemporaneous images that circulate on culture and their associations with different conceptions of beauty, gender and body. More specifically, we are interested in examining how these images interpellate young children in Early Childhood Education and their implications for gender relations and the kind of subject that it forms. We are also interested in the conceptions of beauty, body and gender constructed by children. From the approach to the academic debate on the issue, we aim: to analyze the processes involved in the appropriations made by the children images of female and male body and its relations with the patterns of beauty and normality in circulation on their educational and non-educational spaces.
\end{abstract}

Keywords: Childhood, Early Childhood Education, Body, Beauty, Gender 


\section{INTRODUÇÃO}

O presente artigo visa contribuir com análises que vem sendo desenvolvidas relacionando as imagens que circulam na sociedade contemporânea e as diferentes concepções de beleza, gênero e corpo. Com foco em discussões que trazem uma pauta que interessa à Educação Infantil e seus profissionais, tais imagens interpelam as crianças pequenas que frequentam estes diferentes espaços educativos e estão implicadas no tipo de sujeito que desejamos formar.

As reflexões que apresentamos aqui, ao pensar a produção das diversas concepções de beleza, corpo e gênero pelas crianças da Educação Infantil, são resultado da interação entre pesquisas que vem sendo desenvolvidas no âmbito da Educação em articulação com os estudos da cultura (visual) e que têm como foco os espaços educativos escolares e não escolares.

\section{O CORPO E A EDUCAÇÃO INFANTIL}

O corpo além de ser meio essencial para conhecer e explorar o mundo, é um elemento central na constituição de identidades. Nele se encontram as marcas culturais de gênero, classe social, grupo etário, raça/etnia de uma determinada sociedade. As primeiras descobertas e percepções em relação ao corpo e ao meio social acontecem na infância, sendo assim, é fato que no período referente à Educação Infantil o corpo é muito observado e percebido de diferentes formas pelas crianças. Elas fazem uso deste corpo para se comunicar de forma espontânea com o seu entorno.

As instituições educacionais $e$ escolares são os lugares em que se encontram as maiores possibilidades para as práticas da sociabilidade no período da infância. Reconhece-se que neste espaço educacional, as crianças encontram inúmeras referências para a significação de corpo e formação de sua identidade social, seus valores, cognição, afetividade e outros elementos relacionados ao seu desenvolvimento humano, cultural e social.

Por meio do processo de
significação construímos
nossa posição social, a
identidade cultural e social
de nosso grupo, e
procuramos constituir as
posições e as identidades
de outros indivíduos e de
outros grupos. Produzimos
significados e sentidos que
queremos que prevaleçam
relativamente aos
significados e aos sentidos
de outros indivíduos e de
outros grupos (SILVA, 1999,
p.21).

Para Silva (1999) a identidade é construída relacionalmente e leva em 
consideração o seu par. Olhar para a criança na Educação Infantil é pensar em fortes relações com as diversas linguagens, principalmente através da quantidade de imagens presentes em seu entorno, seja via livros, brinquedos, cartazes, vídeos e outras mídias.

\section{E O QUE DIZER SOBRE AS IMAGENS?}

Ao falar destes bens da cultura que Ihes são dados a ver, usar e valorizar, as imagens estão presentes e fazem parte do consumo visual que participa intensamente do cotidiano das crianças, sem que se tenha uma percepção precisa dos efeitos deste consumo cultural. Estas imagens colocadas em circulação através de livros de literatura infantil, filmes, desenhos animados, entre outros artefatos culturais, produzem efeitos sobre as relações e práticas sociais. Considerar essas relações é falar em cultura visual:

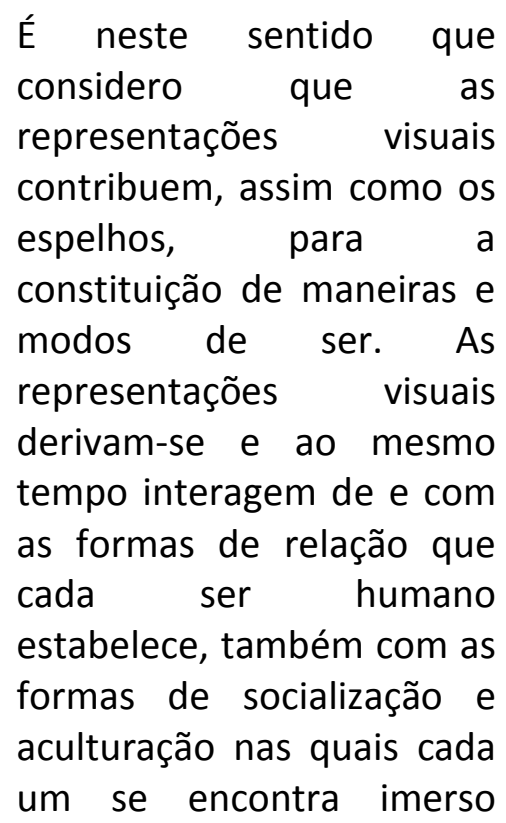

desde o nascimento e no decorrer da vida. (HERNÁNDEZ, 2007, p.31).

Estes artefatos culturais, fazem com que a percepção do corpo não seja a partir de si mesmo, mas de modelos de corpo ideal apresentados às crianças. Através das imagens do corpo, mediadas pela cultura, é definido o que é belo. Os significados que os corpos têm nas práticas de cuidado com a aparência, feminina ou masculina, estão articulados às expectativas da sociedade e grupos sociais a que os sujeitos pertencem.

Vive-se em um tempo em que as imagens são cada vez mais centrais. Esta visualidade ágil e irrefletida deixa claro que o corpo, como imagem a ser difundida e apreciada, necessita ser melhorado, sendo passível de investimentos para os cuidados de si, tendo como guia parâmetros culturais de normalidade.

A preocupação com a aparência sempre existiu, porém, o corpo que antes era renegado e não visibilizado, hoje é extremamente valorizado e exposto. Algo que antes era uma preocupação de adultos, hoje se estende às crianças, mais intensamente às meninas, como é possível constatar na fala de Vitória, de 5 anos, aluna de uma escola infantil durante uma atividade relativa à roda de leitura:

Desenha outra princesa pra mim? Esta aqui sou eu. Ela tá bonita, mas tem os 
cabelos armados como os meus [refere-se aos cabelos presos na parte superior da cabeça por uma fita lilás, crespos e escuros]. Quero uma princesa de cabelo liso, assim, solto, que dá pra pentear [acompanha a fala com o gesto de passar a escova pelo cabelo longo como se o mesmo fosse até o meio das costas]. Pode até ter a minha pele escura, mas o cabelo tem que ser liso! Bem bonito! ${ }^{1}$

Como constatamos na fala de Vitória, o corpo infantil vem sendo alvo de constantes e acelerados investimentos. Com o desenvolvimento dos meios de comunicação e sua cada vez mais intensa inscrição no cotidiano das crianças pequenas, em especial da tevê, estas passaram a ser vistas como pequenos consumidores e a cada dia são alvos constantes da comunicação publicitária (FELIPE; GUIZZO, 2003).

Esta preocupação que atinge fortemente as mulheres, especialmente as meninas, não pode ser entendida como algo peculiar e natural aos sujeitos femininos, mas sim, como parte de um sistema histórico, social e cultural estabelecido e difundido. A preocupação com o corpo e sua aparência é constada desde os primeiros anos de vida, principalmente em relação às meninas. Este aspecto é facilmente notado através do

${ }^{1}$ Este excerto se refere às anotações relativas a relatório escolar de atividades docentes de uma das autoras do presente artigo em escola de educação infantil no município de Presidente Prudente em 26 jun. 2014. O nome utilizado foi arbitrariamente atribuído. intenso crescimento do mercado de cosméticos voltado às meninas pequenas esmaltes para unhas, sombras para os olhos, produtos diversos para os lábios e cabelos.

\section{A BELEZA: MAIS QUE UM CONCEITO}

O belo há séculos atrás era considerado um dom divino e, segundo Sant'Anna (2000), passou a ser pensado como resultado de um trabalho contínuo sobre si, ou seja, não é suficiente nascer bonita, mas é necessário (re)construir todos os dias a beleza que se tem ou que se ambiciona ter. Neste contexto, as múltiplas imagens em circulação por variados artefatos e textos culturais participam da fabricação de corpos possíveis a partir da constituição de imaginários globais e locais articulados em panoramas subjetivos presentes na imaginação de diferentes sujeitos, expandindo as possibilidades de produção de sentido e disseminando práticas e marcas identitárias que constituem culturas em que se inscrevem as crianças contemporâneas. (QUADROS, 2011).

Velho (2006) assinala que há muitas maneiras de ser jovem e prolongar o ser criança. Tais classificações não são dadas, e sim, construídas e discutíveis, sujeitas a redefinições, reinterpretações em diferentes contextos históricos. Assim, podemos pensar com Hall (1999) que as identidades são múltiplas, instáveis, construídas 
culturalmente. A diferença marca a identidade e faz ver o seu caráter relacional.

Desta forma, a partir de Giddens (2002), consideramos que, relativamente às identidades infantis e os corpos das crianças, eleger um padrão de beleza corporal é parte de uma espécie de projeto de constituição identitária sempre em construção a partir da escolha de modelos que a cultura, principalmente no âmbito do consumo, oferece em um processo de reflexividade contínuo de construir-se a si mesmo a partir de uma oferta de modelos que se multiplicam através das narrativas em circulação.

De acordo com Meyer (2002, p.55) "os discursos constroem e implementam significados na sociedade por meio de diferenciações que dividem, separam, incluem e excluem e que, por se constituírem em dinâmicas de poder, produzem e legitimam o que, aí, é aceito como verdade". No âmbito da cultura ocidental contemporânea, as diferentes narrativas predominantemente as midiáticas e visuais difundem representações de um determinado tipo de corpo valorizado e tomado como ideal a ser buscado.

Quaisquer características que fujam a tal padrão cultural de beleza fazem com que os corpos sejam muitas vezes rejeitados, modificados, retificados, "consertados" através de processos que vão desde a prática de exercícios físicos intensos e consumo de alimentos saudáveis, passando por distúrbios alimentares com efeitos sobre a imagem de meninas muito jovens, até a solicitação, quase exigência, de intervenções cirúrgicas para adequação ao modelo ideal (MELLO, 2009). Não estar de acordo com tais padrões é, muitas vezes, tomado como sinônimo de falta de cuidado e vontade, decorrentes de baixa autoestima; os corpos são considerados como diferentes, "defeituosos".

Neste sentido, é a partir dos discursos colocados em circulação através de diferentes narrativas sobre que o é ser "belo" que os padrões se estabelecem. O conceito de beleza depende da estrutura social e cultural de uma sociedade. É verdadeira a ideia de que cada organização social possui sua própria concepção de beleza.

As temáticas como corpo, beleza e gênero poderiam ser trabalhadas e discutidas com as crianças desde os espaços destinados à Educação Infantil. Tais espaços, porém, não costumam ser lugares em que o corpo em sua dimensão humana, social e estética seja visibilizado, reconhecido e discutido. Isto é, não ocorrem intervenções de forma tão deliberada ou planejada, conquanto isso ocorra o tempo todo nas interações ali vivenciadas.

As manifestações infantis são provenientes de uma cultura própria das crianças. Suas expressões, em variadas 
linguagens, decorrem da relação com a cultura que as cerca, ou seja, pode-se dizer que as significações das imagens presentes no cotidiano infantil influenciam suas, identidades, autoimagem e também, comportamento corporal, atravessadas por relações de gênero.

\section{RELAÇÕES DE GÊNERO, IMAGENS DIZENDO COMO SER MENINA/MENINO}

Deste modo, é possível afirmar que as crianças constroem suas identidades de gênero à medida que são identificadas, social e historicamente, como masculinos ou femininos (LOURO, 1997). As identidades e diferenças são produzidas não apenas via discursos e saberes, mas também por meio das interações que elas estabelecem entre si e com os adultos. Suas práticas expressam as apropriações particulares que fazem daquilo que vivem e observam, em seus contextos de vida.

As relações entre as crianças nos diferentes espaços educativos sofrem os efeitos de outras intervenções, tais como: a organização dos espaços, as imagens dispostas no ambiente, os brinquedos $\mathrm{e}$ materiais diversos. Estes elementos interferem no comportamento das crianças e suas práticas de sociabilidade tendendo a normalizá-las.

Estas intervenções diferenciam meninos/meninas e seus corpos, sendo significativas para refletir sobre a produção de discursos hegemônicos de feminilidade e masculinidade que circulam em narrativas endereçadas às crianças. Em função do gênero, destacamos ainda a diferenciação dos banheiros, das brincadeiras, a presença de carrinhos, armas, bonecas e artefatos de cozinha, as formas de organizar os grupos para determinadas atividades, além de condutas ditas corretas e incentivadas para os meninos e as meninas como "meninos não choram" ou "meninas são delicadas", são outros exemplos de intervenções.

Felipe (1999) complementa esta ideia ao afirmar que brinquedos, bonecos, jogos diversos, programas de televisão nos dizem uma série de coisas, indicando-nos modos de ser e sentir, constituindo-nos como sujeitos. Desta forma, acreditamos que artefatos acessíveis às crianças pequenas, tanto nos ambientes educativos quanto no ambiente doméstico produzem efeitos de sentido no que se refere aos corpos, beleza/feiura e conduta social das crianças, negando-as como sujeitos de direitos e produtoras de culturas.

OS ARTEFATOS CULTURAIS E A INFÂNCIA, ALGUNS ESTUDOS SOBRE CORPO E BELEZA

As imagens produzidas para a infância são altamente sugestivas, convidativas e sedutoras na medida em que oferecem representações de crianças e infâncias 
socialmente aceitas e consideradas desejáveis (ABREU, 2010). Há princesas e príncipes, heróis e vilões, meninos e meninas que parecem mostrar as diferenças, mas que, como argumentado por Steinberg e Kincheloe (2001) e Kellner (2001), fornecem recursos que ajudam a construir uma cultura "infantil" aparentemente comum para a maioria das crianças em muitas regiões do mundo.

A literatura infantil, os vídeos assistidos na escola e as imagens em materiais escolares como estojos, mochilas, cadernos; paredes ornamentadas, cartazes, roupas, calçados, alimentos infantis e publicações de vários gêneros fazem com que as crianças entrem em um mundo de significações colocadas em circulação pelas mídias, conforme constatado pelas pesquisas de Costa e Momo (2010). Como destacamos anteriormente, mais importante para a menina Vitória do que ser representada como uma princesa negra, de cabelos crespos e olhos grandes e escuros, era ser bonita como aquela do filme: de cabelos lisos e olhos verdes, ainda que de pele negra.

Neste sentido, não se pode descartar a ideia de que todos estes artefatos culturais são planejados e produzidos por adultos. As escolhas, preferências e aprovação estão amplamente condicionadas à ideia do adulto e ao que se pretende com estes materiais diante da educação das crianças.
Dentre as pesquisas realizadas com base em estudos das imagens presentes na infância e com foco nas relações de corpo, gênero e beleza, Bonin e Silveira (2010) discutem as marcas das diferenças através das formas corporais em personagens gordos da literatura infantil e tecem uma crítica aos valores morais que ficam implícitos e estão de maneira desigual presentes nas obras literárias contemporâneas para crianças. As autoras observaram como são colocados saberes e maneiras de falar sobre a gordura corporal, articulados à preocupação em ensinar aos pequenos leitores como evitar esta gordura e aceitar sua condição de alguém "diferente". Ou ainda, corrigir o "problema", transmitindo a mensagem que retirando do corpo a gordura que está sobre ele é torná-lo, novamente, corpo normal.

Sabat (2004) desenvolveu uma pesquisa sobre os filmes para crianças, dentre eles, clássicos que estão presentes da rotina da Educação Infantil. Segundo a autora, as narrativas veiculadas por estes produtos culturais ensinam a ser menino e a ser menina. Os filmes infantis, então, parecem ser inocentes, entretanto, estão repletos de mecanismos de controle e regulação, apresentando aos sujeitos condutas socialmente aceitas, de modo a marcar identidades que fogem à normalidade. Porém, para que haja um outro aproveitamento deste material, seria 
importante proporcionar às crianças outros olhares sobre diferença, gênero e o corpo biológico/social.

As imagens dispostas nos espaços da Educação Infantil também são objeto de pesquisas no campo da Cultura Visual. Neste sentido, Cunha (2006) destaca que os materiais que envolvem e fascinam as crianças, muitas vezes são intencionalmente produzidos a fim de propor determinadas narrativas sobre o mundo. As formas de lê-las e percebê-las instituem experiências visuais, modelam a percepção. As práticas do olhar produzidas pela indústria de entretenimento envolvem imagens de fácil adesão, estereotipadas, simplificadas. Estas imagens produzem "saberes" e "verdades" sobre o mundo: valores éticos, estéticos, de gênero, raça, étnicas, formas de agir e de ser, os modos das relações com os outros.

\section{ALGUMAS CONSIDERAÇÕES}

As instituições voltadas à Educação Infantil são espaços que podem oferecer múltiplas possibilidades para o exercício de práticas de sociabilidade das crianças pequenas. Neste sentido, reconhece-se que ali elas encontram inúmeras referências para a formação de sua identidade social, seus valores, cognição, afetividade e outros elementos relacionados ao seu desenvolvimento humano, cultural e social.
Em vista disto, entendemos ser importante e urgente colocar-se em discussão os efeitos da produção intensiva e propositada das imagens nas esferas comercial, midiática, cultural e escolar destinadas às crianças. Neste sentido, retomamos aqui a indagação que tomamos como título do presente artigo - Corpo, gênero e beleza: o que a educação infantil tem a ver com isso? - para afirmar que toda a comunidade e profissionais envolvidos na educação de crianças "tem a ver com isto". Todos são responsáveis e deveriam se comprometer com a discussão sobre as imagens que circulam nos espaços educativos, pois elas estão implicadas na concepção de sujeitos que desejamos formar. Assim, cabe aos educadores mediar as relações entre as crianças e as imagens que as interpelam nos seus diferentes espaços de convivência, incluindo-se aí os espaços educativos.

\section{REFERÊNCIAS}

ABREU, Luciane. Bruxas, Bruxos, Fadas, Princesas, Príncipes e outros bichos esquisitos....As apropriações infantis do belo e do feio nas mediações culturais. 2010. Dissertação (Mestrado em Educação) Programa de Pós-graduação em Educação, Faculdade de Educação, Universidade Federal do Rio Grande do Sul. Porto Alegre.

BONIN, Iara T. SILVEIRA, Rosa M.H. As formas do corpo: marcas da(s) diferença(s) em personagens gordos da literatura infantil. 
Currículo sem Fronteiras, v. 10, n. 2, p. 7790, jul/dez. 2010.

COSTA, Marisa Vorraber; MOMO, Mariângela. Crianças Escolares do Século XXI: para se pensar uma infância pós-moderna. Cadernos de Pesquisa, São Paulo, v. 40, n. 141, p. 965-991, set/dez., 2010.

CUNHA, Suzana R. V. As imagens na educação infantil: uma abordagem a partir da cultura visual. Revista da Associação de Professores de Expressão e Comunicação Visual, Porto, n. 46, p. 4-11, jul. 2006

FELIPE, Jane. Entre tias e tiazinhas: pedagogias culturais em circulação. In SILVA, Luiz Heron (Org.). Século XXI: qual conhecimento? Qual currículo? Petrópolis: Vozes, 1999.

FELIPE, Jane; GUIZZO, Bianca Salazar. Erotização dos corpos infantis na sociedade de consumo. Proposições, v. 14, n. 3, p. 119130, set/dez. 2003.

GIDDENS, A. 2002. Modernidade e identidade. Rio de Janeiro: Jorge Zahar Editor.

HALL, Stuart. A identidade cultural na pósmodernidade. Rio de Janeiro: DP\&A, 1999.

HERNÁNDEZ, Fernando. Catadores da cultura visual: transformando fragmentos em nova narrativa educacional. Porto Alegre: Mediação, 2007.

KELLNER, Douglas. A cultura da mídia. Trad. de Ivone Castilho Benedetti. Bauru, SP: EDUSC, 2001.

LOURO, Guacira L. Gênero, sexualidade e educação: uma perspectiva pósestruturalista. Petrópolis: Vozes, 1997.

MELLO, Luciana Maria Hoff. Campanhas Publicitárias 'Vendendo Saúde': discurso 'científico' e consumo construindo modelos de vida saudável. 2009. Dissertação (Mestrado em Educação) - Programa de Pósgraduação em Educação, Faculdade de Educação, Universidade Federal do Rio Grande do Sul, Porto Alegre.

MEYER, Dagmar E. Das (im) possibilidades de se ver como um anjo. In: GOMES, Nilma L.; SILVA, P. (Orgs.). Experiências étnicoculturais na formação de professores. Belo Horizonte: Autêntica, 2002. p. 51-70.

QUADROS, Marta Campos de. Tá Ligado?!: práticas de escuta de jovens urbanos contemporâneos e panoramas sonoros na metrópole, uma pauta para a Educação. 2011. Tese (Doutorado em Educação) Programa de Pós-Graduação em Educação, Universidade Federal do Rio Grande do Sul, Porto Alegre.

SABAT, Ruth. Só as bem quietinhas vão casar. In: MEYER, Dagmar Estermann; SOARES, Rosângela de F. Rodrigues (Orgs.). Corpo, gênero e sexualidade. Porto Alegre: Mediação, 2004. p. 95-106.

SANT'ANNA, Denise. Descobrir o corpo: uma história sem fim. Educação e Realidade, Porto Alegre, v. 25, n. 2, jul./dez., 2000. p. 4958.

SILVA, Tomaz T. O currículo como fetiche: a poética e a política do texto curricular. Belo Horizonte. Autentica: 1999.

STEINBERG, S. R.; KINCHELOE, J. L. Introdução. In : STEINBERG, S. R. \& KINCHELOE, J. L. (orgs.). Cultura infantil: a construção corporativa da infância. Rio de Janeiro: Civilização Brasileira. 2001.

Recebido para publicação em 20/08/2014 Revisado em 01/09/2014

Aceito em 20/09/2014 